\title{
Analysis of Interpersonal Relationship Differences between Chinese and Americans
}

\author{
Yang Liu, Dali Niu* \\ English Department, Foreign Language School, North China Electric Power University, Baoding, Hebei, China
}

DOI: $\frac{10.36348 / \text { sijll.2020.v03i06.001 }}{\text { | Received: } 17.05 .2020 \mid \text { Accepted: } 26.05 .2020 \mid \text { Published: } 12.06 .2020}$

*Corresponding author: Dali Niu

\section{Abstract}

With the development of globalization, cross-cultural communication has become more and more important. Under different cultural backgrounds, interpersonal relationships vary greatly. The differences in interpersonal relationship have an important influence on the communication between Chinese and American people. Exploring the differences of interpersonal relationship between Chinese and Americans is of great significance for guiding people to better crosscultural communication. By the comparative analysis of the interpersonal relationship between Chinese and Americans from three aspects: family relationship, friendship and teacher-student relationship, this paper explores the specific manifestation of differences and the causes behind them, and further puts forward reasonable solutions to the promotion of the cross-cultural communication between the two peoples.

Keywords: Interpersonal relationship; family relationship; friendship; teacher-student relationship; Chinese; Americans.

Copyright @ 2020: This is an open-access article distributed under the terms of the Creative Commons Attribution license which permits unrestricted use, distribution, and reproduction in any medium for non-commercial use (NonCommercial, or CC-BY-NC) provided the original author and source are credited.

\section{INTRODUCTION}

Interpersonal relationship plays a very important role in communication. Due to the influence of different cultures and social environments between China and America, people have formed different world views and values, as well as different cognitive methods and behavioral norms. Therefore, under different cultural backgrounds, people's ways of dealing with interpersonal relationships are also very different.

This paper attempts to study the differences between Chinese and American interpersonal relationships, based on some research data in the field of cross-cultural communication. There have been many studies on the differences between Chinese and American interpersonal relationships at home and abroad, but they only put forward the outline of the differences, and did not explore the differences in depth. Therefore, it is of great value to further explore the differences between Chinese and American interpersonal relationships by means of comparative analysis, especially for Chinese living in America.

\section{The Differences on Interpersonal Relationship between Chinese and Americans}

Generally speaking, Interpersonal relationship can be reflected in many aspects, which involve family relations, friend relations, teacher-student relations, employment relations, etc. In this paper, the author focuses on the differences of interpersonal relationship between Chinese and Americans from three aspects, including family relationship, friendship and teacherstudent relationship.

\section{Differences on the Family Relationship}

Traditional Chinese families exist in the model of stem family, but in America, the nuclear family model dominates the society [1]. So, there are differences between Chinese and Americans on who are family members. In China, the traditional family is a large family with multiple generations living together under one roof. Chinese people tend to include uncles, cousins and grandparents, etc as family members. And the big family is the ideal model in traditional Chinese culture, where multiple generations of family members living together symbolize unity, happiness and prosperity. The traditional Chinese belief is that family is the fundamental unit of the society, whose inner harmony guarantees the stability of the society. However, the American family is typical of the small nuclear form. If Americans name an immediate family, they refer to husband, wife and their children. Uncles, cousins, grandparents, etc are considered as extended family, which are regarded as relatives. 
Chinese families focus on the close relationship among family members, hoping that both parents' love for their children and children's gratitude to their parents can last a lifetime. Children usually live with their parents until they get married, and parents would like to bear all the expenses of their children before they initiate the action of leaving to live alone. When they grow up, children choose to settle down and work near their parents, in that on the one hand, they hope to get support, spiritually and on their life and work because they are so inexperienced and on the other hand it is convenient for them to take care of their parents, also spiritually and on the life as the parents grow older. As for American families, they pay attention to cultivating their children's independent spirit. Generally speaking, children have their own rooms since childhood. When they are seven to eight years old, their parents encourage them to do some simple work to earn pocket money. Children leave their parents to live independently after they grow up at eighteen, or after they graduate from universities. It is also rare for parents to live with their children when they get old or after they retire, and thus they choose to live by themselves or in nursing homes. If children live with their parents after they become adults, they usually have to pay their board and lodging and elderly parents will do the same if they live with their adult children, both of which are seen by Americans as signs of independence.

In addition, in China, parents often give compulsory advice to their children in many aspects, no matter in studying, working or living. For example, when children face the choice of a university, their parents will strongly recommend which university to apply to and what major to learn. When children graduate, parents will choose jobs for them and try all their means to settle down the jobs for them. But in America, children should make their own decisions from an early age and parents usually respect their children's decisions. For example, children can decide which school they prefer to go to and what kind of work they choose to do, and whom they would like to get married to, and which city they want to live in, as long as it is concerned with their private life. As we can see, the meaning of family means differently in the two countries. In traditional Chinese culture, the interests of individual are often subject to the interests of family. However, in America, it is often individual centered and family status is less important. When the individual interests conflict with those of family, the first thing people concern about is not family expectation but individual wishes.

The differences of family relationship between Chinese and Americans are also reflected in the relationship between mother-in-law and daughter-inlaw. In China, a young married couple usually forms an extended family with the husband's parents. So in this case, relationship between mother-in-law and daughter- in-law is an important relationship in this large family because China is a country that promotes filial piety, which is one of the core Chinese cultural values. Therefore, daughter-in-law should show filial piety to her mother-in-law. At the same time, mother-in-law also helps her daughter-in-law with various things in her daily life, such as taking care of children. The relationship between mother-in-law and daughter-inlaw is very close because they are a family. But in America, children, male or female, declare independence when they reach 18 years old or get married. They establish their own families and begin to live independently. Therefore, American women don't live with their parents-in-law after marriage. Both mother-in-law and daughter-in-law have their own families, and they don't interfere with each other. Mother-in-law doesn't help daughter-in-law look after children, because it is known that raising children is parents' responsibility in America and mother-in-law has not the obligation to take care of the children. The relationship between mother-in-law and daughter-inlaw is distant.

\section{Differences on the Friendship}

Due to different cultural backgrounds, Chinese and Americans have different understandings on the concept of "friends". To Chinese, those who are called friends are always lifelong close friends. Friendship is the result of long-time contact and association. When making friends, Chinese emphasize characters and interests. So Chinese are cautious in making friends. They need to know each other quite long and in depth before they become friends. However, in the eyes of Americans, friends are partners who share the same preferences and can easily play together. When choosing friends, they lay emphasis on a person's external demeanor, communication ability and ability to create a pleasant atmosphere. Therefore, Americans are more open and casual in making friends with no need to have in-depth understanding of people. Even people who meet for the first time may be regarded as friends.

Chinese often go through long-term contact and get to know each other before they become true friends. Friendship usually lasts forever, no matter where they come from and no matter what they do. Some people even think that only after experiencing big events can people cultivate deep friendship. Taking "Oath in the Peach Garden" (the friendship between Liu Bei, Guan Yu and Zhang Fei in The Romance of Three Kingdoms) is a good example. Friendship like this once established is always lifelong. The Chinese hope that friendship will be everlasting and unchanging, so they would use every means, though parted, to keep the treasured friendship such as online chatting, phone calls, travelling together, etc. On the contrary, Americans are different in this issue, their friendship develops rapidly but disappears rapidly [2]. The high mobility of Americans is well-known all over the world. It is the high mobility that makes the friends circle of 
Americans change frequently. Americans may soon shift their enthusiasm for their friends from one person to another just because they have changed jobs or moved houses. Therefore, Americans may have many good friends at one time, but such friendships are often related to certain circumstances. Once circumstances change, so do friends.

Different understandings to the concept of "friends" and different ways of making friends lead to different expectations to friends between the Chinese and American people. Chinese expect that their friends can help them in time and any time when they encounter difficulties. And those who are regarded as friends are ready and willing to give a hand all the time. Therefore, Chinese have high anticipation of friendship. In contrast to Chinese, Americans are relatively independent. In their daily life, they treat their friends sincerely and help each other. But they prefer to be independent and rely on themselves rather than seeking help from their friends when they encounter difficulties. Even so, they would ask their friends in advance whether it is convenient for them to do the favor. As a result, Americans have low anticipation of friendship.

\section{Differences on the Teacher-Student Relationship}

There are also differences in teacher-student relationship between Chinese and Americans. In China, teachers, as the imparters of knowledge, are regarded as the center of class. There are differences on position between teachers and students. In Chinese classroom, there is usually a platform in the front of the classroom that is placed opposite the students' desks. The students' desks are arranged in rows. The platform is the teacher's fixed territory, generally $10-15 \mathrm{~cm}$ above the ground. When a teacher stands on the platform, he is higher in position than all the students sitting there. This not only reflects the authority of teachers, but also reflects the unequal position between teachers and students. In America, students are the center in teaching activities. Teachers are organizers of class or assistants to the students in their studies. Teachers and students have the equal position. In the classroom, you can hardly recognize which position belongs to the teacher because teachers often cooperate with students, and thus they either walk around the classroom or help solve problems among students. They have not certain positions.

In China, for thousands of years, teachers have been endowed with the duties of teaching and enlightening the mind. Teachers are pleased and are able to help students solve problems. Teachers are strict, but they care for their students. The relationship between teachers and students is just like that between father and son. There is a Chinese proverb, one who teaches you one day is your father forever, which can prove the relationship between teachers and their students. In America, teaching and learning are more like a fare exchange. For teachers, they have the responsibility of teaching because they are paid. As for students, they pay tuition fees, and then they have the right to be enlightened by the teachers. But the relationship between teachers and students is not as close as the relationship between Chinese teachers and students.

In the aspect of teaching, Chinese and American teachers have different attitudes towards students' questions and silence. When students ask questions, Chinese teachers always think that the students have not listened carefully because teachers believe that the students should not have questions if they listened carefully. As for the silence of students, teachers think that the students have understood what they says and have successfully completed the teaching without difficulties. However, American teachers like students to ask questions actively in class. They think this is the positive response of students to what they have said. In this way, if students have any problems, teachers and students can communicate in time. As for the silence in class, teachers think that the students do not listen carefully or do not understand what they have just taught.

In addition, Chinese teachers usually regard students as members of the class, hoping that students consider the mutual interests of the class and win more honors for the class. However, in America, teachers pay attention to the personal competition ability, advocate developing students' personalities, and hope individuals to do the best [3].

\section{Factors Influencing Chinese and American Attitudes towards Interpersonal Relationship}

There are many factors influencing the differences of interpersonal relationship between Chinese and Americans. In my opinion, the most important factors are the following value differences: Collectivism vs. Individualism, Morality vs. Law and Stability vs. Mobility.

\section{Collectivism vs. Individualism}

The root of the differences in interpersonal relationship between Chinese and Americans is that they have their own cultural orientations. China is a collectivism-oriented society while America is an individualism-oriented society [1]. These differences are closely related to Confucius' philosophy in China and western religious philosophy in America. Chinese put emphasis on collectivism and one of the Chinese core ideas to show collectivism is "Ren", which is one central element in Confucianism. "Ren" teaches people to be ideal persons, that is, people should be kind and warm to others or respect others. Further, an ideal person has good interpersonal relationships in society and is able to cope with relations between personal and collective interests correctly. Therefore, under the influence of "Ren", Chinese people attach great importance to the construction of interpersonal 
relationships as well as tend to put the collective interests first. Besides, Confucius' "Ren"(仁), the writing of its Chinese character is left-and-right form, with its left part(人) meaning "people"and its right part( 二)"two", so the Chinese word"Ren"means "two people", which tells us to integrate into the collective family. On the contrary, Americans emphasize individualism. Christianity, as the dominant religion in America, which believes that the world is created by God and the human being is created according to God's own image [3]. Everyone is important and has a special relationship with God as well as enjoys the God-given rights and freedoms. Americans believe that disrespecting individualism is against God's will. In addition, the Constitution of the United States also attaches importance to the value of individual freedom. Thus, individualism is formed in a certain cultural background. As a result, Americans think highly of individual independence, affirming personal success. They put the individual first while dealing with individual and collective interests.

\section{Morality vs. Law}

Chinese emphasize morality while Americans emphasize law, which is another important reason for the differences between Chinese and American interpersonal relationships. In traditional Chinese morality, "Face" culture is an important ingredient. It requires people to respect others and think of others' feelings in any circumstances. Sometimes, people can even give up their principles for the benefits of their friends. Under the background of "Face" culture, Chinese attach great importance to the construction of interpersonal relationships. In the eyes of Chinese, more friends make the journey easier. However, for Americans, no one is above the laws. The Declaration of Independence, upon which the United States was founded puts forward:

... and to assume among the Powers of the earth, the separate and equal station to which the Laws of Nature and of Nature's God entitle them...

We hold these truths to be self-evident, that all men are created equal, that they are endowed by their creator with certain unalienable rights, that among these are life, liberty, and the pursuit of happiness.

In a word, everyone is equal before not only God but also laws. If all people are laws-abiding, everything can be solved smoothly. Therefore, In Americans' daily life, people usually deal with business according to laws rather than relationships with others.

\section{Stability vs. Mobility}

Another important reason of differences in interpersonal relationship between Chinese and Americans is that the high stability of Chinese and the high mobility of Americans. China is a typical agricultural country and people depend on the land for a livelihood. Chinese believe that only by cultivating their fields can they live from one generation to the next. So Chinese emphasize stabilities, including job stability, friendship stability, life stability and so on. In Chinese opinion, people won't live a happy life until everything is stable. On the contrary, America is an immigrant country with the population from all over the world. Americans believe that mobility leads to a better life. So Americans move frequently to different towns, cities or even different countries. So we can see that Americans' interpersonal relationship is unstable, especially friendship. Their friendships depend on frequent interaction with others. If the people do not see their friends for a long time or they do not interact with each other regularly, the friendships will disappear [2].

\section{Ways to Deal with the Differences of Interpersonal Relationship between Chinese and Americans}

In order to achieve effective cross-cultural communication, first of all, we should accept the culture differences between China and America, and then we should keep positive attitudes on cultural differences and understand each other's culture.

\section{Keeping positive attitudes towards Cultural Differences}

The different cultural backgrounds hold the most important reason to the interpersonal relationship differences between Chinese and Americans. There is no good or bad culture. Each culture embraces its own distinctive charm. It is necessary for us to treat other cultures with the attitudes of respect and tolerance. By the way, we can not only broaden our horizons but also solve problems smoothly. On the contrary, negative treatment of cultural differences will destroy the effective communication, even cause conflicts in culture.

\section{Understanding Each Other's Culture}

People have formed different values under different cultural backgrounds. It is inevitable that some people are unwilling to learn the unfamiliar culture. However, only through mutual learning, can we comprehend each other better. Therefore, it is necessary for Chinese and Americans to learn each other's culture. There are many ways to understand each other's culture. For example, reading literature, watching movies, travelling and communicating with the locals, etc. What is better is to reject the bad and adopt the good. In this way, we can understand why other people behave in that way. This will not only stop us from judging others' behaviors by our own cultural values, but also pave the way for communication.

\section{CONCLUSION}

Comparing the differences of interpersonal relationships between Chinese and Americans is not to judge which is good or not, but to understand the differences, treat the differences reasonably, and better understand one's own culture and the other's culture as well. The culture of any nation has its own 
characteristics and is worth learning by other nations. The differences of interpersonal relationships between Chinese and Americans reflect the differences between Chinese and American cultural traditions.

Interpersonal communication under the Chinese culture is implicit, indirect and based on collectivism, while interpersonal communication under the American culture is explicit, direct and based on individualism. In this paper, we see the diversity of interpersonal relationships and learn how to respect the differences between Chinese and American interpersonal relationships. Through the contrastive analysis, this paper enables us to have a better understanding of the potential problems in crosscultural communication and deal with cross-cultural interpersonal relationships effectively.

No culture is superior, nor is inferior to other cultures. Chinese people hold to Chinese culture while American people keep to theirs. We should recognize, respect and learn from different cultures. Only in this way can we find the best way to overcome the obstacles in the process of interpersonal communication and create a harmonious atmosphere for interpersonal communication.

This paper is one of the research achievements of "Research on the Solution of the Contradiction between Chinese Cultural Promotion and Chinese Cultural Aphasia in College English Teaching" (No. HB18YY033) supported by Social Science Foundation of Hebei Province in 2018.

\section{REFERENCES}

1. Pan, X. (2016). A Comparative Analysis of Interpersonal Relationships between Chinese and Westerners [J]. Labor Security World, (21).

2. Yao, S. (2012). A Comparative Study on Friendship in Chinese and American Cultures [J]. Journal of Hubei Correspondence University, (7).

3. Fan, X. (2008). A Comparison of Interpersonal Relationships under Chinese Collectivism and American Individualism [J]. Henan Education, (11). 